\title{
Network diversity and educational attainment: a case study in China
}

\author{
Ka Yi Funge
}

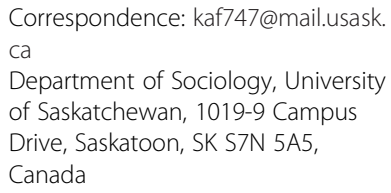

Correspondence: kaf747@mail.usask. ca

Department of Sociology, University of Saskatchewan, 1019-9 Campus Drive, Saskatoon, SK S7N 5A5, Canada

\begin{abstract}
This qualitative study looked at network diversity and educational attainment. In the summer of 2008, in-depth interviews were conducted with 30 undergraduate students from two of the most prestigious universities in China-Peking University and Tsinghua University. Twenty respondents came from a rural background and the other 10 were from urban areas. It was found that the educational support networks of the rural students were generally larger than those of their urban peers. This is because they faced more barriers than the urban students and their network members were less able to provide them with resources, so they needed more supporters in their journey to elite colleges. The findings indicate that rural students do not get enough help from the state and therefore have to rely on their own resources to achieve academic mobility.

Keywords: Social network; Educational attainment; Elite university; China
\end{abstract}

\section{Springer}

\section{Background}

This paper aims to investigate how the composition of a support network shapes academic performance. Studies following the line of research instigated by James Coleman show that educational attainment is not simply an individual process but a collective one in which students access different kinds of social capital that can facilitate their academic performance (Kim 2005). Empirical studies have documented the positive effects on students' schooling of the social capital embedded in their educational support networks (Teachman et al. 1996).

However, not every student has an educational support network that can provide such social capital. Composition is a key factor accounting for the amount of social capital embedded in any given social network. A large and diverse social network contains more social capital than a smaller and less diverse one (Lin 2001). People who have such a large network are more likely to receive greater benefits from the use of social capital in situations such as looking for a better job (Son and Lin 2012).

There are many factors that shape the size and diversity of a network. These parameters are dictated to a large extent by social and demographic background. Women, ethnic minorities, the poor, and other disadvantaged groups tend to have a smaller, less diverse social network and consequently to reap fewer benefits (Lin 2001).

(c) 2015 Fung. Open Access This article is distributed under the terms of the Creative Commons Attribution 4.0 International License (http://creativecommons.org/licenses/by/4.0/), which permits unrestricted use, distribution, and reproduction in any medium, provided you give appropriate credit to the original author(s) and the source, provide a link to the Creative Commons license, and indicate if changes were made. 
As noted by Blau and Schwartz (1984), network composition is also constrained by the macro social structure. For instance, if there are no black people in your community, you are less likely to have black members in your social network.

Based on this perspective, network composition could be a factor accounting for students' educational achievement. It may be suggested that students from advantaged groups will tend to achieve academic success as they will be more likely to have large and diverse networks that can provide them with rich social capital, while the reverse will be true for disadvantaged people.

However, some students from disadvantaged groups do still achieve academic success. For example, $34 \%$ of students at UC Berkeley receive Pell grants which are intended to support students from low-income families (Perez-Pena 2013). How and why are these students able to succeed, given that their educational support networks are supposedly less diverse and smaller than those of students from advantaged groups?

To answer these questions, the study reported here investigates the differences in the composition of the educational support networks of students from advantaged and disadvantaged groups. It also looks at how these networks can enhance educational attainment.

\section{Educational resources}

Education level has a significant influence on one's social position. Schultz (1988) points out that the labor market demands well-educated employees because they are fully equipped with professional knowledge or skills and so, in turn, will have higher productivity. Therefore, people should invest more in their education so as to be more competitive and obtain a good job.

Given the emphasis among human capital theorists on the importance of education level in affecting one's future, it is essential to ask who can access such higher levels, such as tertiary education. Educational opportunity is not evenly distributed, even if it is increasing overall (Mare 1980). A comparative study undertaken by Shavit and Blossfeld (1993) shows that educational expansion has had very little impact on the elimination of the impact of family background on students' educational attainment. In the case of rural students in China, for example, proportional enrolment in universities has failed to keep pace with the overall rate of expansion, even though there are many more rural than urban students. Among those aged 25-29, only $1.4 \%$ of rural residents had a college education in 2005 compared to $9.8 \%$ of urban dwellers (Wu 2010).

Social network theorists suggest that inequalities in educational attainment between groups are mainly caused by the different chances of accessing educational resources from network members. Research shows that educational resources are a decisive factor in producing good academic performance (Buchmann and Hannum 2001). These resources include intelligence, material resources (Brown and Park 2002), cultural capital (DiMaggio 1982), information (Kim and Schneider 2005), social connections (Coleman 1988), educational aspirations, and perseverance (Nicholas et al. 2008). Students can access these resources based on their social ties but do so to a very different extent depending on the amount available. Those rich in educational resources can do well in school, while those who lack them seldom excel. Therefore, differences in the ability to 
access social capital between members of different social classes contribute to inequalities in education (Coleman 1988).

Given the importance of educational resources, a brief introduction is required to what they are, how they function, and how they enable social networks to affect educational performances.

The first kind of resource is intelligence, which means "the possession of knowledge, the ability to use information processing to reason about the world, and the ability to employ reasoning adaptively in different environment" (Bernstein et al. 1994: 368). According to Herrnstein and Murray (1994), the level of one's intelligence is genetically decided, such that members of some races have more than others. In contrast, social reproduction theorists argue that intelligence is not genetically but socially determined, because the forms of knowledge valued by society are selected by advantaged groups. In order to protect their privilege and ensure the success of their children, the powerful elite celebrate only the knowledge of their own culture, upper-class culture, through the education system. Thus, only students who are familiar with upper-class culture are praised as intelligent, while those who are not are described as not intelligent enough to do well in school.

Some scholars also highlight that intelligence alone does not adequately explain achievement but is only one among many factors affecting success and failure. Instead, more attention should be paid to the social world and the macro social structure in order to explain individual achievement more fully (Fischer et al. 1996). This means it is essential to review other resources that will shape one's academic performance.

The second kind of resource is material resources, which refers to money for study or other physical goods. Although many governments provide free compulsory education, still money can provide students with extra resources such as supplementary exercises, private tutors, or extracurricular activities (Harris et al. 2008) or help students overcome learning problems by consulting specialists, such as psychologists (Wu 2007). These additional supports can improve students' performance at school.

The third resource is cultural capital, which is "general cultural background, knowledge, disposition, and skills" (Macleod 1995: 13). These cultural skills and knowledge can help students to acquire a familiarity with school culture. Thus, they would be less likely to give up study (MacLeod 1995).

The fourth resource is information. Information can enhance educational attainment by informing the student about additional ways to achieve success in school, such as tips for preparing for examinations, and making informed decisions, like information about college selection (Kim and Schneider 2005).

The fifth resource is social connection. Social connection refers to instrumental ties through which useful resources can be acquired (Bian 1994). During the socialist era in Czechoslovakia and Russia, unqualified students could get into a good school or college by their social connections with the headmaster of that school or college (Wong 2002).

The sixth resource is educational aspiration, which refers to one's ambition to get a good education. If one has higher educational aspiration, one will be more willing to spend time studying, or at least less willing to give up, and thus will have a better chance of getting extraordinary results at school (MacLeod 1995).

The last resource is perseverance-the will to work hard and not give up in the face of difficulties. For example, with perseverance, a girl from a disadvantaged group can 
still do well at school, regardless of being homeless, sleeping in shelters, and studying in the worst school in the district, while most of her peers may give up (Portes and Fernandez-Kelly 2008).

\section{Educational resources, social capital, and network diversity}

The educational resources discussed above are often accessible through social ties. According to Nan Lin (2008), social capital means resources embedded in social ties. These resources can be accessed through one's direct and indirect ties and facilitate actions towards one's goals. Many students, particularly primary school pupils, do not possess the aforementioned educational resources themselves. They have to get them from others. Educational resources flow through social networks.

Coleman (1988) applies social capital theory to studying educational achievement. In his classic study Social Capital in the Creation of Human Capital, he demonstrates how social capital embedded in kinship ties influences students in their schooling processes. If parents and children have a close relationship, the latter can access social capital as a result so will be more likely to perform well in school. This arises for several reasons. Firstly, parents can transmit their educational expectations to their children, leading to the latter developing higher aspirations for themselves. Secondly, children can get more help from parents when they need support, such as helping them with their homework. Thirdly, these children may be closely supervised by their parents and this supervision can avoid children learning bad behaviors (Coleman 1988).

Following Coleman's approach, both qualitative (Portes and Fernandez-Kelly 2008) and quantitative studies (Kim 2005) have identified four sources of social capital to enhance academic performance: parents, teachers, peers, and communities. For example, parents can provide material resources and information to their children, help them to develop high educational aspirations, encourage them, and transmit cultural capital to help them get into a university (Ono 2004). Teachers can help students to develop high educational aspirations (Goyette and Conchas 2002), connect them to government institutions to win scholarships, and provide information and encouragement. Peers can also provide encouragement. Furthermore, through community ties, one can access information about schooling (Zhou and Bankston 1998).

The number of educational resources embedded in one's social network is partly influenced by its diversity. From a social network perspective, students need educational resources to continue their schooling. These resources are embedded in their social network. The ability to provide resources is affected by network members' own social background. If they are similar, such as being of the same gender, they tend to provide very similar resources. In contrast, if network members come from diverse social backgrounds, such as different class positions, they can provide different resources, such as information from the middle and lower classes (Lin 2001). Therefore, it can be said that having a large and diverse educational support network makes it more likely that one can access different kinds of educational resources. In other words, network diversity can influence one's chance of succeeding at school through the provision of such resources.

In summary, this section has explained why social capital is expressed in social networks containing educational resources and shown that the social network is a key 
factor influencing access to these educational resources. The next section therefore reviews the impact of network diversity on the use of social capital.

\section{Framework}

Studies of social capital show that network composition affects the amount of social capital available (Erickson 2003). A large and diversified network enables people to explore more resources from remote areas because it can cut across the boundaries of social circles and thus alleviate the negative effects of in-group constraints on resources (Son and Lin 2012). For example, the disadvantaged can benefit from having a more diverse network by accessing information and influence through ties with the more advantaged, thereby accessing resources that are usually unavailable to disadvantaged groups. It is also useful for the majority, since it facilitates access to the resources of the minority with high socioeconomic status. A large and diversified network can thus benefit both the disadvantaged and advantaged.

Disadvantaged and advantaged groups do not have equal opportunities to develop a large and diverse network. As the former are located at the bottom of the social strata, they do not have many chances to meet people from the upper social classes. Even if they do have that chance, people from such advantaged groups may not be as willing to develop ties with members of lower class groups. Using the job-seeking process as an example, the advantaged may fear that if they help the less advantaged, the latter will harm their reputation by not working as hard (Smith 2005).

As well as social status, heterogeneity also affects intergroup relationships. Heterogeneity means having a mixture of members of different social groups in one's network. In a highly heterogeneous community, we are more likely to make friends with those from different groups, such as people of different ethnicities or occupations. The opportunity to develop intergroup relationships is reduced in a less heterogeneous community as there are fewer opportunities to come into contact with diverse people (Blau and Schwartz 1984).

The literature suggests that people in disadvantaged groups and in less diversified communities tend to have a smaller social network. How does this affect the case of schooling? Theoretically, students from disadvantaged groups will tend to have a smaller educational support network. However, some do still perform well at school despite their network limitations-is this because their networks are as effective as those of students from advantaged groups? How do the educational support networks of students from advantaged and disadvantaged groups differ in terms of composition?

To answer these questions, this paper compares the composition and functions of the educational support network of students from advantaged and disadvantaged groups. Such a comparison can allow us to picture the composition of the educational support networks of the two groups and thus show us the differences in the networks, their functions, and the process of mobilizing social capital.

This paper also investigates how the network structure changes during the process of educational attainment. Very few, if any, studies have looked at such changes. The tendency has been to focus on only one kind of social capital, such as information, one type of network member, such as teachers, and a specific time period, such as high school (Ono 2004). Consequently, the limited number of studies could reflect a limited 
variation in network structure. However, networks are dynamic. The educational support network one has during the school years is likely to be different from that found at the university stage. Studying this dynamic process can reveal the factors accounting for changes in network structure and hence chart their impact on academic performance.

The findings of this study may afford us a deeper understanding of how educational support networks affect educational stratification. By studying the way network composition influences the effect of social capital on schooling, we can identify the forms of network that can best facilitate good performance. Furthermore, this also allows us to examine whether the composition of the educational support networks of students from disadvantaged and advantaged groups is different, and if so, the impact of these differences on academic performance.

\section{Context of China}

This study looks at the case of China, where the labor market places a high value on job seekers' educational qualifications. Since the economic reforms, foreigners have been allowed to invest in mainland China. This economic reform process, in addition to advances in technology, has boosted economic development. Thus, the labor market has a large demand for skilled and trained workers, such as employees who can speak foreign languages or who have specific professional knowledge (Qin et al. 2013).

Because of the high demand for well-educated employees, there has been an increase in the number of people returning to education (Zhang et al. 2002), from 4 to $10.2 \%$ during the period 1988-2001 (Zhang et al. 2005). Daily off-farm earnings increased by $30 \%$ for senior high school graduates and $57 \%$ for university graduates from 2003 to 2007 (Qin et al. 2013). It is therefore important for rural young people to have more schooling.

Although educational achievement is very important in China, there are very large differences in the academic performances of students from rural and urban areas, with the attainment of the former usually being lower. For example, the rural and urban illiteracy rates in 2010 were 7.26 and $1.9 \%$, respectively (National Population Census, 2010). For urban youth who were between 15 and 19 years old in 2010, $53 \%$ were in senior high school and $17.88 \%$ were in tertiary institutions while the percentages for the rural youth were 30 and $2.6 \%$ (National Population Census 2010).

This huge variation in educational attainment is mainly due to three factors. One is the shortage of resources among local governments. Since the 1980s, the financing of education has undergone a great change. The central government is no longer the only financial supporter of primary and secondary education. County governments and levels below them are also responsible for this (Tsang and Ding 2005). Local governments in economically advanced areas can provide more resources for education, but in less economically advanced areas, they do not have enough resources for this. These poorer local governments are usually found in rural areas. As a result, rural schools provide fewer resources for students than urban schools (Hannum and Park 2007). For example, the per-student spending of urban primary schools was 1062 RMB in 1999, and that of urban high schools was $1439 \mathrm{RMB}$, while the equivalent figures for rural schools were 576 RMB and 851 RMB, respectively (Tsang \& Ding 2005). 
The second reason for the urban-rural variation in academic performance is school resources. Students in schools with better qualified teachers and more resources are likely to perform better in tests (Hannum and Park 2007). Schools in rural areas almost always have fewer resources than urban schools. For instance, in 1990, only $23.64 \%$ of rural senior high school teachers were full time (Hannum 1999), while the urban rate was much higher. Without qualified teachers and resources, rural students are likely to perform less well than urban students.

Thirdly, the differences in the resources received from families contribute to the gap in performance. Table 1 shows that the income gap between urban and rural areas is very large and is growing. This means that urban families are more likely than rural families to provide their children with resources. For example, some rural families have to spend $50 \%$ of their cash income on their children's education. Some need to borrow money from friends and relatives to do so. Students from these families are as much as three times more likely to drop out of school than students from rich families (Brown and Park 2002).

Rural families are also less able to provide cultural capital to students. Without the cultural skills and knowledge needed at school, rural students face greater obstacles to academic success (Andreas 2004).

Despite all these difficulties, some rural students still excel in their academic performance. For instance, in the late 1990s, around 12-15\% of students at Peking University, an elite college in China, came from villages (Liang et al. 2012). Using China as an example, this study tries to identify the impact of network composition on access to educational resources in students' journeys to such elite colleges. By studying the educational attainment process of both rural and urban students who have succeeded in gaining admission to one of the most prestigious universities in China, we can obtain an insight into the formation of students' educational support networks and the impact of those networks on their performance in school. We can also investigate the differences in the educational support networks of the two groups of students.

\section{Methods}

In this qualitative study, data were collected using semi-structured in-depth interviews. The interviews were conducted between April and June 2008 on the campuses of two universities-Peking and Tsinghua. Four topics were included in the interview: the

Table 1 Income per capita in urban and rural areas

\begin{tabular}{lll}
\hline & Income per capita in urban areas (RMB) & Income per capita in rural areas (RMB) \\
\hline 1978 & 343.4 & 133.6 \\
1980 & 477.6 & 191.3 \\
1990 & 1510.2 & 686.3 \\
1995 & 4283 & 1577.7 \\
2000 & 6280 & 2253.4 \\
2002 & 7702.8 & 2475.6 \\
2004 & 9421.6 & 2936.4 \\
2006 & $11,759.5$ & 3587.0 \\
2008 & $15,780.8$ & 4760.6 \\
\hline
\end{tabular}


respondents' family situation, their educational support network before they went to college, their view of the national college entrance examination, and information about their study at the university.

There were several criteria used to select the respondents. They were required to be undergraduate students studying at Peking University or Tsinghua University at the time of the interview. Rural respondents had to have rural household registration status and have lived in a village (not a small town or county). Their parents also had to have rural household registration status, so they could work in or outside the village, but could not have their own shop or company. The urban respondents had to have urban household registration status and to have lived in a non-rural area. Their parents had to have urban household registration status and could not be peasants.

There were three ways I used to find respondents. One way was through my own network. I asked my friends who were studying at Peking University and Tsinghua University and a professor who was teaching at Tsinghua University to spread the recruitment message. Secondly, I posted a recruitment message on a popular online forum of Peking University. A few days later, some respondents contacted me via email and phone message as they wanted to do the interview. Thirdly, the president of the Rural China Society of Peking University helped me to spread the recruitment message to members. During the interest club promotion week, I saw the promotion counter of the Rural China Society. I asked the president whether or not the society could help me to find some respondents and they agreed to send an email to their members and forward their replies to me.

In total, 33 students in both universities were interviewed, of whom 20 were rural and 13 urban. Names have been changed to protect their anonymity. Respondents included students in years 1-4 at both universities. Three rural respondents were from ethnic minorities. Only five of the rural respondents were female. The rural respondents came from nine provinces, the majority of which were western or central. Five of the urban respondents were female and eight were male.

With regard to the respondents' parents, there were big differences in educational level and occupation across the two groups. Most rural respondents' parents had a low educational level ranging from illiteracy to junior high school. A considerable number were peasants, two were storekeepers, one was a Muslim scholar, and the rest were migrant workers. The educational level of the parents of urban respondents ranged from junior high school to graduate school. Their occupations were more diversified than the parents of the rural respondents, ranging from factory workers, housewives, professionals, and university professors to government officials.

A name generator was used to create respondents' educational support networks. This involves asking the question: "Who do you think had the most important effect on your studies?" for each of three stages: primary, junior high, and senior high school. Respondents were asked to limit their helpers to five in each stage. They were then asked about those helpers and their influence. After all the interviews had been completed, it could be seen that the respondents had mentioned practically the same type of helpers for each stage. A general network structure could thus be delineated for the rural and urban respondents in each stage.

In this study, the rural respondents were poorer than those from cities. One may think that rich people in rural areas and poor ones in the city have been excluded. It is 
true that some rural people are richer than some urbanites, but due to their limited knowledge of upper class culture and their low educational level, these parents are less likely to provide students with educational resources beyond money, especially cultural capital.

\section{Results and Discussion}

In this paper, respondents' schooling is divided into three stages, namely primary, junior high, and senior high school, in order to map the influences of network members on educational performance at each stage. Most previous studies have focused on the effect of network members on students within a particular time period, such as senior high school (Kim 2005). However, schooling is a long process, during which students meet a range of people and come against different problems at each stage. These people and problems may shape the formation and function of their support network. In other words, the network is dynamic. Therefore, we can only obtain a deeper understanding of how the network changes and how students and network members change its pattern and function by studying the schooling process as a whole.

Figure 1 depicts the structure of the rural respondents' educational support network at the primary school stage. At this stage, students mainly received help from their parents. Once their parents could offer no more financial support, they asked their friends, relatives, and neighbors for help. For instance, Xiao Qiang said that

my parents valued education very much. When I was very young, my family's financial situation was very bad. Sometimes, we were unable to afford the tuition and fees. Nevertheless, they would borrow money from relatives, or they got the money in other ways, such as saving by not buying new clothes. Their first priority was our education. For example, when I needed to pay the book fees in primary school, my parents did not have any money. They asked relatives and friends to borrow money. [Interviewer: Were they willing to help?] Um ... sometimes.

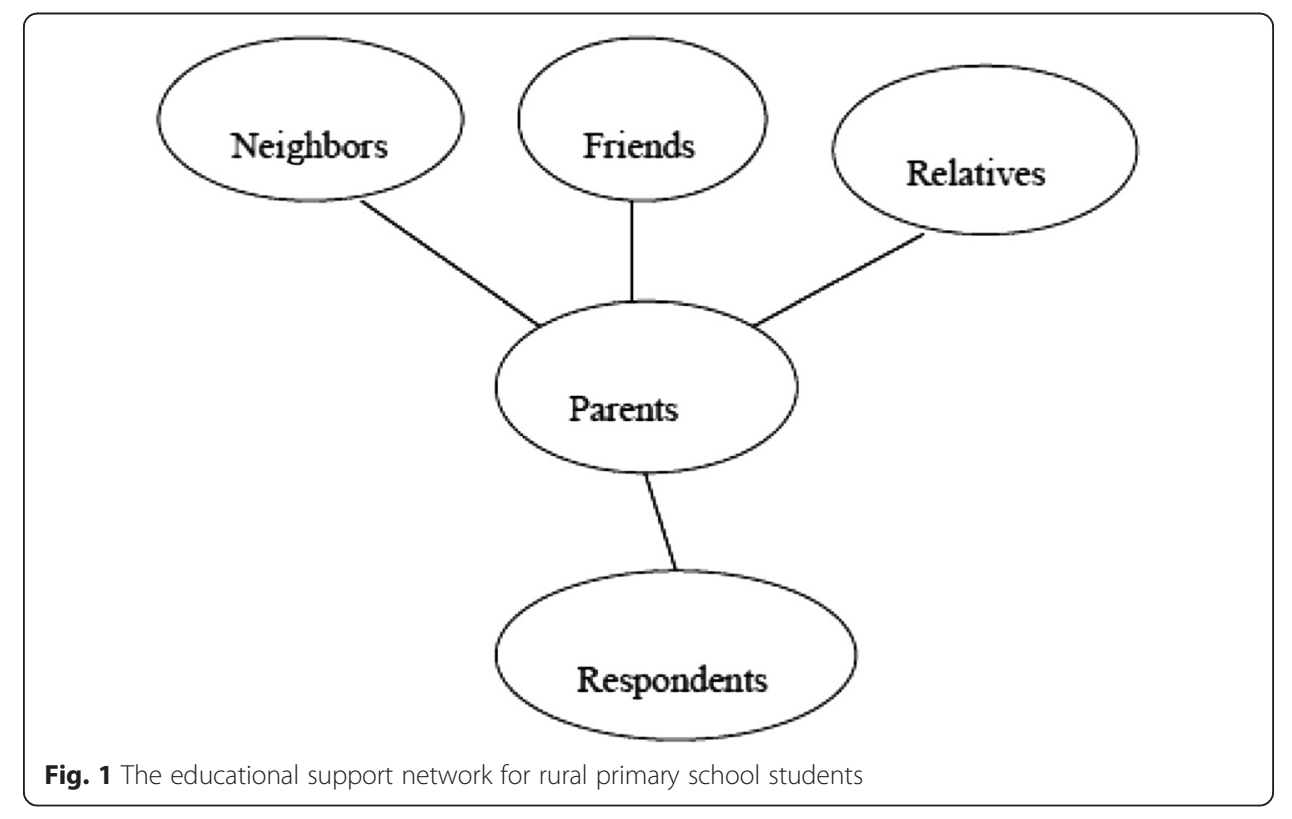


It was not easy, especially when you asked them for money ... but ... you had to ... it was quite embarrassing, right? They were not rich ... we did not have rich friends ... anyway, it was a tough time for my family.

Besides solving financial problems, parents also helped the respondents to develop higher educational aspirations. Xiao Wen recalled that

my mother said "I do not blame anyone for our harsh life. But I hope that you do not struggle as much as us." Life in the village is really tough. It is particularly difficult for my family, which has three kids studying. My family is very poor. My parents have suffered from poverty. They do not want us to suffer from poverty too. They can only earn a living by farming as their educational level is not high. They do not want us to have that life. Therefore, when I was very young, they taught me the importance of getting into university. As a result I also aspired to attend college.

Figure 2 shows the structure of the urban respondents' educational support network at the primary school stage. At this stage, like the rural respondents, they were mainly helped by their parents. Unlike the rural respondents, the urban respondents' parents did not need to ask others for help as they could afford all the materials their children needed and helped them develop high educational aspirations. When I asked them whether their parents had needed to borrow money to support their schooling, all the urban respondents said no; some even stressed that their families had had no financial difficulties.

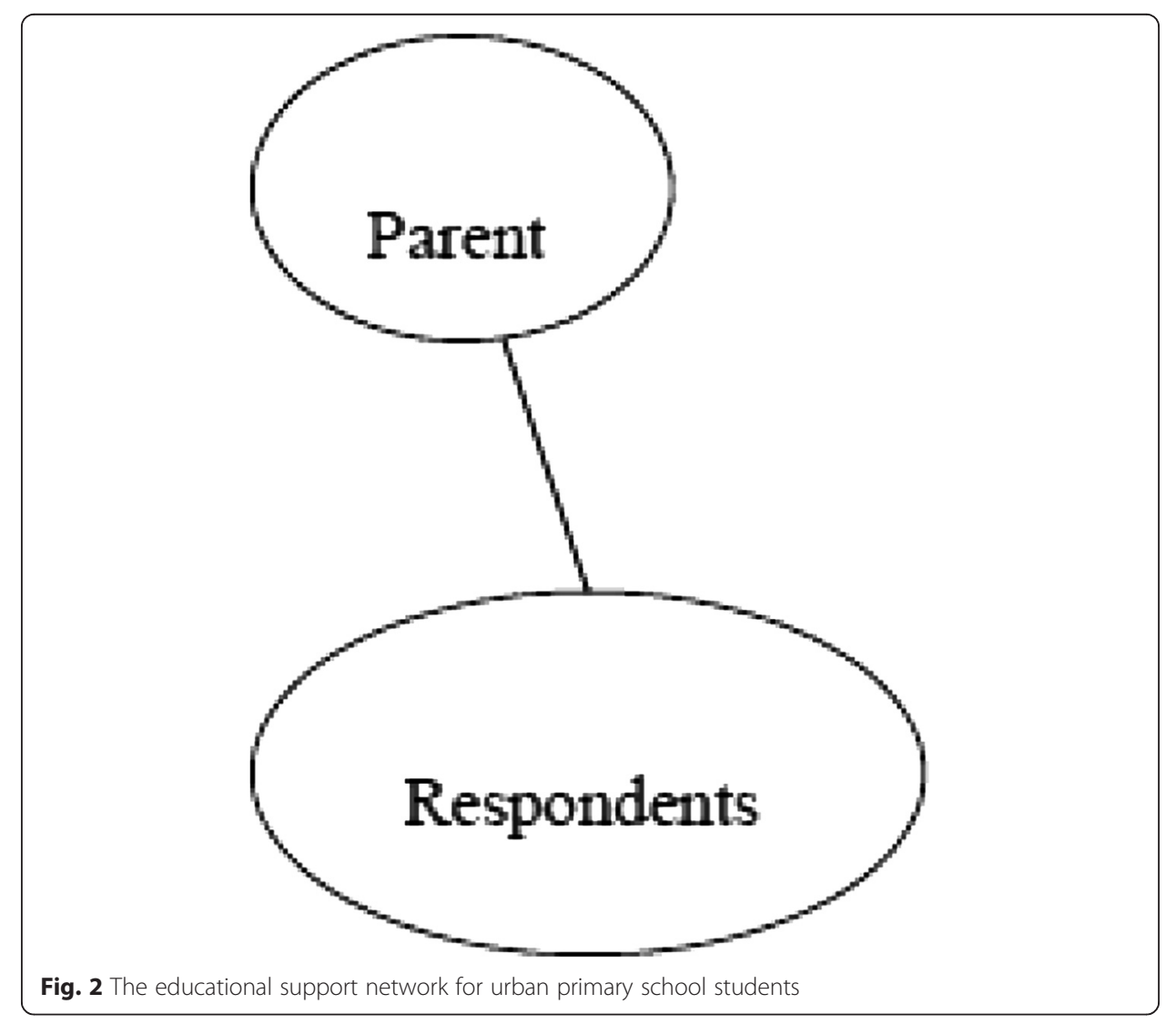


Furthermore, unlike the parents of the rural respondents, the parents of the urban respondents were able to seek out useful information to increase their children's chances of achieving academic success. Xiao Tao's mother is a good example. When Xiao Tao was in kindergarten, his mother began to develop strategies to help him get into a good university. She finally realized that participating in the Olympic Science Competition was a good way to achieve this goal. She chose a primary school which was known for success in this competition. Xiao Tao did very well in the competition and finally got into Peking University as a result, just as his mother had intended.

Figure 3 shows the structure of the rural respondents' educational support network at the junior high school stage. At this stage, their main source of finances was still family, who began also to provide emotional support. Also, almost all the rural respondents were living at their schools, as there are very few good junior high schools in rural areas. If they had not lived at school, they would have had to spend half the day traveling.

At this stage, parents' encouragement helped rural respondents not to give up in this new environment. Overall, they all commented that they had felt stressed in junior high school. However, to avoid worrying their parents, they seldom spoke about the pressure. Luckily, even though their parents had very little experience of school, they still understood that studying alone in the city was not easy, especially since they were not rich, so they gave their children encouragement. All the respondents said that their parents would say to them "do not worry about the money. Just tell us when you need some. We will send it to you immediately. Just take good care of yourself." They explained that the only problems their parents could solve were financial problems, so their parents kept reminding them that money was not a problem in order to help them relax. Although it did not actually help much, the respondents said they did feel encouraged.

Xiao Xiong: Although they [parents] could not really help me, still, I felt blessed when they said they would sell everything to support me. When I cried in bed at night, I would recall their encouragement. It gave me courage to keep it up [laughs].

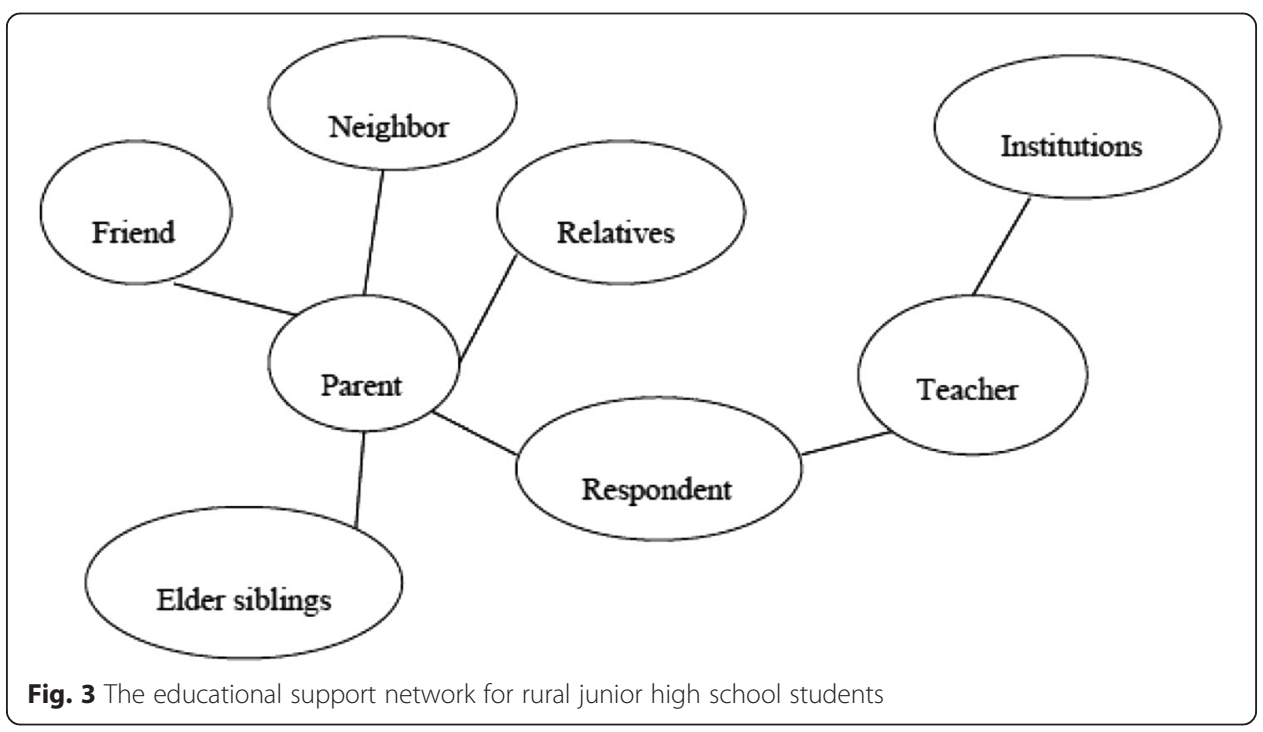


Xiao Zhang: On my first day of senior high school, my classmates laughed at me because I was the only one who did not know what a MP3 player is. I felt ashamed. Because of this cultural shock, I kept doing very well in school in order to stop classmates laughing at me. I was the best student in the class. It was very stressful. When college entrance examinations were coming, I almost gave up. But I went back to my home for a long weekend. I did farm work, housework, and talked with my family. I felt refreshed and energized to continue my study. This was because I saw my parents working very hard in this harsh environment. They can work hard, therefore so can I.

Meanwhile, teachers became a new source of social capital at this stage, for two main reasons. Firstly, most respondents lived at school once they had started junior high. As their parents were not around, they were more likely to seek help from teachers. Secondly, the respondents faced more complicated study issues, with which their parents were no longer able to help. They thus had to seek help from teachers with such issues, such as finding information to help them choose a university.

Teachers' participation in this network linked the respondents to institutions as well. There are institutions which provide help to rural students, such as scholarships, and these will ask teachers to recommend students for their subsidy schemes. Teachers thus became bridges connecting the respondents to these institutions.

Figure 4 depicts the structure of the urban respondents' educational support network at the junior high school stage. As before, the network comprises parents alone, who continued to support the cost of the respondents' schooling. They also provided extra resources to help their children get into better schools. For example, Xiao Zhu's mother hired a private tutor to teach her physics in the evenings. Xiao Lee's parents hired a very famous singing teacher to teach him. As a result, he did very well in a singing competition, which led to him winning a place at Peking University on a specialist program. It can be seen that as their parents could afford to meet all their material needs, the urban respondents did not need to seek help from other sources.

Moreover, unlike the rural respondents, the urban respondents had had no difficulties getting used to the new school environment because their parents had passed their cultural capital to them so that they were very familiar with urban culture. Xiao Zhu recalled that her parents would take her to museums at the weekends. Xiao Lee and Xiao Lo said that they had traveled during the holidays.

Figure 5 shows the structure of the rural respondents' educational support network at the senior high school stage. At this stage, parents were still responsible for providing financial support and encouragement to their children. The role of teachers was becoming more important, as rural students faced more academic problems here than in the previous two stages. Xiao Zhang's experience illustrates the importance of teachers in providing information. At the beginning of senior high school, Xiao Zhang had to choose which class he wanted to attend. He said that

I understood that only the students in the class for poor students could get the 200 RMB subsidy per month. So I gave up the Olympic Science Competition class and chose the class for poor students. My class teacher asked me why I had given up the competition class. He told me that students who were not in the class for poor 


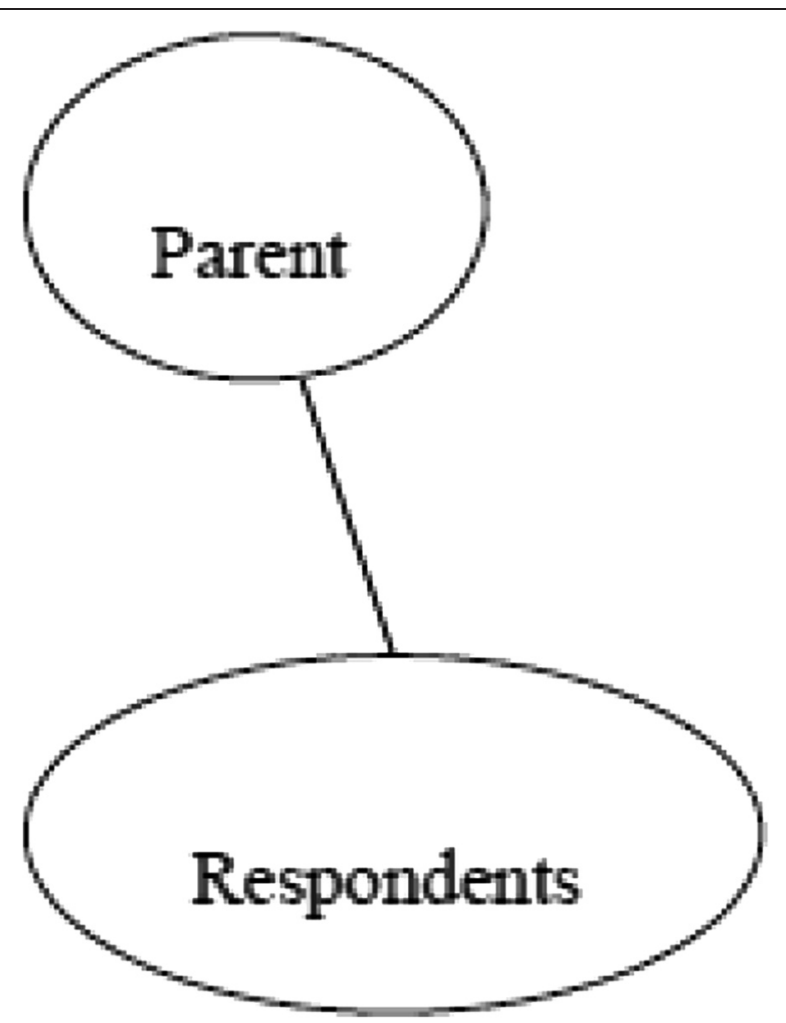

Fig. 4 The educational support network for urban junior high school students

students could still get the subsidies. He also reminded me of the importance of ambition. In the end, I did not join the class for poor students.

Later on, Xiao Zhang did very well in the Olympic Mathematics Competition, which led him to win a place at Peking University.

Teachers' roles involved more than simply giving information to students. They also provided material resources. Tuition and books are more expensive at the senior high school stage, so students have a heavier financial burden. Teachers knew that rural

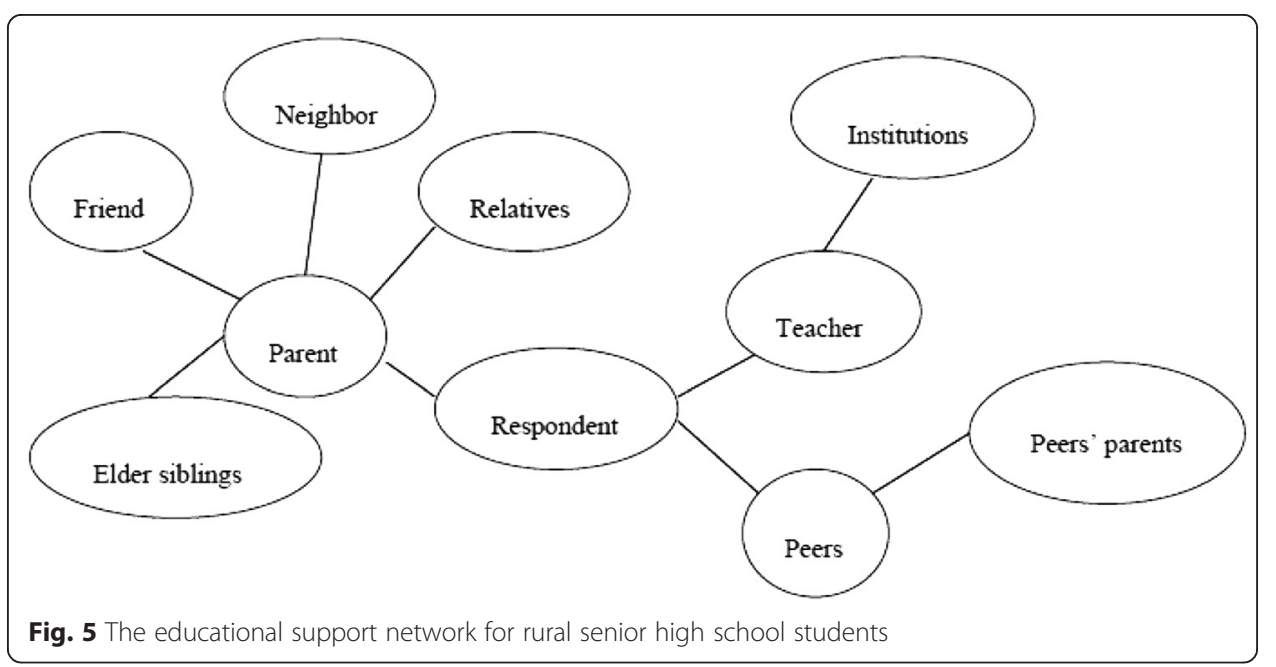


students might have difficulties meeting this financial challenge and may feel stressed, so they sometimes offered them a hand.

Xiao Mei: My class teacher sometimes gave me money so that I could buy more food. This teacher came from a rural area too, so he understood the difficulties I had.

Xiao Long: I did not have the money to buy textbooks, so I read the books in the bookstore every weekend. My class teacher knew this, and told me to buy all the books I needed, and then she reimbursed me the money.

Some teachers may think that giving students money directly is not appropriate. Instead, they offer other material resources.

Xiao Xiong: When I was in senior three, I could not afford the residential fee. My teacher allowed me to live in her home free of charge. She even gave me breakfast every day.

Besides tangible resources, teachers' encouragement was important for the students to form higher aspirations. Although all the rural respondents had studied in very good senior high schools, they were still not sure whether they were good enough to go to prestigious universities because there were almost no university graduates in their villages. They thus tended to have low aspirations and to target less famous universities. Once their teachers realized that they were lacking in confidence, they began to encourage them to aspire to higher profile universities. Xiao Feng remembered that he had never aspired to Peking University, but his class teacher kept encouraging him. In senior one, the teacher told him that he had the ability to get into a good university, so he should try his best and work harder. In senior three, the teacher suggested he aim for Peking University as his performance was good enough. Xiao Feng said that without this teacher's encouragement, he would not have considered elite colleges.

At this stage, peers also joined the network. The respondents faced more problems than in earlier stages, particularly in terms of pressure. They tended to seek emotional support from their peers because it was easier for them to understand their feelings. They were all facing the same challenges.

Xiao Xiong: Um ... it was very important. It meant you did not feel lonely. When you saw how hard your classmates worked, you were motivated. You felt that you were a team fighting a common enemy: the college entrance examination. It was very much like a war. We all had the same target.

Xiao Wen: I'll always remember my two best friends in senior three. One of them was a boy, and the other a girl. They helped me a lot. The girl always helped me to buy lunch and dinner and chatted with me. The boy was my buddy. Both of us did very poorly in mathematics. We got the worst grades in the mathematics tests and examinations. As both of us did poorly in mathematics, it was easier for us to understand each other's problems. 
In addition, if their peers were unable to help, they could recruit help from their parents. Thus, their peers' parents also became a source of social capital. Xiao Long said that

for example, my roommate in my senior high school was not as poor as I was. His mother often came to visit him on weekdays, and she would give me some old clothes as they always bought new clothes. During festivals, she also invited me to go out to have dinner or lunch and gave me a lot of food. And she always asked me if I had any difficulties or not and about my family situation.

Figure 6 shows the structure of the urban respondents' educational support network at the senior high school stage. At this stage, parents were still in the network, but a new member had joined-teachers. Once respondents moved to senior high school, they felt more pressure as they were afraid of doing badly in the college entrance examination. They would seek encouragement from their parents, but since they had begun living at school to avoid wasting time traveling, they could not see their parents everyday, so they sometimes spoke to their teachers about the stress. Also, the teachers now had more time to observe and so could find out whether or not their students were under stress and encourage them when necessary.

One may ask why classmates did not provide support to urban respondents. This was raised several times during the interviews, and the respondents said they felt strange and even annoyed about the idea of asking peers for support. As one explained, peers are just friends. They would socialize together and chat during leisure time. But when he had an academic problem, he would ask teachers for help or ask parents to hire private tutors, instead of asking peers who cannot help them. Also, he did not want to show weakness to his classmates. While rural respondents needed peers' encouragement to keep working hard, the urban respondents felt they did not need others to encourage them to study. It was taken for granted that everyone, including them, would attend university. As Xiao Huang put it, "if I don't study, I do not know what I can do. You do not need to think why you will attend university."

In summary, there were differences in the composition of the educational support network of the two groups of students studied here. The rural respondents had more members in their network, namely family, teachers, and peers. More importantly, these members were bridges connecting them to others with whom they might have otherwise been unable to develop ties by themselves. In contrast, urban respondents had a smaller network, in which family members were most important, followed by teachers in the latter stages. Also, they had no indirect ties.

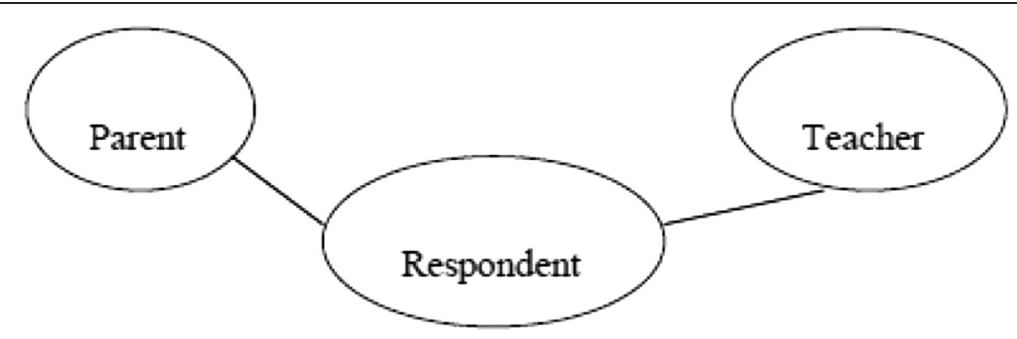

Fig. 6 The educational support network of urban senior high school students 
These two groups also had different sources of social capital. Their stories show that rural students sought out social capital from more diverse sources. They obtained material resources from family, teachers, peers, and other members connected by indirect ties. Urban students, in contrast, received material resources only from their parents. Another kind of social capital is educational aspiration. Both rural and urban respondents had been taught by their parents to have high aspirations. Teachers also encouraged rural students to work hard and aim high. With regard to information, rural respondents usually obtained information from teachers while their urban compatriots tended to get it from parents or seek it out themselves. There was one educational resource that rural respondents could not get from their network; cultural capital, which is mainly transmitted from parents to children. Urban parents passed their own cultural capital to their children, such as by visiting museums or traveling. However, rural students' parents had very limited knowledge about the urban environment, foreign countries, or even life outside their village. Thus, it is possible that they had no cultural capital to give.

\section{Conclusion}

This paper shows that, in the educational process, successful students from disadvantaged groups tend to have a more diversified and larger network than students from advantaged groups, unlike the process of occupational attainment. From the figures given, it can be seen that at the primary school stage, urban students' networks consisted solely of parents, while the members of rural students' networks included parents, relatives, and neighbors. At the senior high school stage, rural students' networks included parents, relatives, neighbors, siblings, teachers, peers, peers' parents, and institutions. Such networks are much larger and more diversified than those of urban students.

In contrast, peers, tutors, or communities are missing in urban respondents' educational support networks. When urban students only mentioned parents and teachers as their network members, I kept asking whether or not there were other network members who had offered them assistance. As mentioned earlier, they all thought that they did not have any difficulties that could not be solved by parents or teachers and felt that it was strange to ask them this question. Some of them even felt annoyed. For example, Xiao Li, a respondent from Guangzhou city, emphasized that "Well, I should tell you that my family do not have any problem. My parents can satisfy all my needs. And I do not have any academic problem. You just need to pay attention in the class, follow teachers' instruction and work hard."

This difference between the educational support network of rural respondents and urban respondents shows that the composition of network members is shaped by members' ability to provide social capital. According to existing literature, peers, tutors, and communities are the main sources of social capital, but this may not apply in the case of urban respondents. However, the majority of these studies target immigrants or students from disadvantaged groups (Kim and Schneider 2005, Portes and FernandezKelly 2008). Migrant families are not familiar with the local education system, so they need information from others, such as local communities. For disadvantaged groups, parents of these students have limited resources for their children's schooling. As a result, they have to get help from others. However, the urban respondents in this case are 
different. Their parents' ability to provide resources to students is higher than parents of migrant students or those from disadvantaged groups. These parents were able to tackle most of the problems their children encountered. For example, even if teachers did not provide financial aid, they could still afford all the fees and costs of schooling. With regard to academic problems, urban respondents emphasized their academic capabilities, suggesting they did not have academic problems that could not be solved by teachers or by themselves.

For rural respondents, however, the situation is totally different. Their parents have access to fewer resources and are therefore unable to solve the problems their children face. Taking the financial burden as an example, if relatives, neighbors, teachers, and the government cannot provide assistance, rural respondents may even have to drop out of school if they cannot afford to continue. It is thus essential for them to seek help from people outside their family.

As rural students need wider support, the changes in their support networks reflect their chances of attending universities. In the later stages of education, these respondents had more difficulties, so they and their network members sought outside help. As more and more people offered assistance, the respondents' educational support networks kept getting larger. In other words, if networks are static, people may fail to get help from others, are more likely to fail to overcome these problems, and may have to give up studying.

One may ask why non-family members are willing to help rural respondents. There are two possible explanations. Culturally, Chinese people pay great attention to education. They are thus willing to help all good students achieve academic success. From a more selfish perspective, having a successful student is good for a teacher's career, so teachers will help students who have the potential to get into elite colleges. Furthermore, elite college graduates are very likely to get good jobs. If a teacher offers to help a rural student get a place in an elite college, he or she may later become a useful member of that teacher's social network, in turn. Therefore, it can be said that helping rural respondents is an investment that may have a high return in the future. Since network members themselves were not interviewed here, future research should focus on them in order to investigate the reasons they are willing to help. This would give us a better understanding of the factors influencing network size and diversity.

The difference in network structure indicates that network structure may be related to the formation of educational stratification. Comparing these two groups of elite college students shows that even though both achieved academic success, those from disadvantaged groups required much more social capital to get there than their more advantaged peers. If rural students had the same network structure as urban students, they would probably fail to win places at elite colleges, because they would be unable to access enough social capital to resolve all their difficulties. They need a larger and more diverse network that allows them access to more social capital. However, not all students from disadvantaged backgrounds are as lucky as our rural respondents were in having such a large and diverse network. Such students cannot mobilize enough social capital to tackle all the problems they face, and this limitation is likely to result in them failing to get into elite colleges. In other words, having a diverse social network is one of the keys to achieving academic success for people in disadvantaged groups. Meanwhile, the difficulty of establishing a large and diverse educational support 
network is a factor causing educational stratification. Future studies should pay more attention to the challenges involved in establishing a network full of resources and the influence of network composition on educational stratification.

Furthermore, although the rural students studied here achieved academic success through the help of network members, this alone does not mean that network members' support can equalize urban and rural students' chances of attending universities. A lack of cultural capital in their educational support network leads rural respondents to have fewer chances to attend universities than their urban peers. It is true that access to college in China is mainly based on scores in entrance examinations. However, the stories told by urban respondents showed that they have two ways of increasing their chances under this system.

Firstly, there is a specialist student program in place at most institutions. If students are very good at sport, music, or art, some universities (including elite colleges) will give them 10-20 credits in their entrance examinations. For example, if Xiao Lee had not earned 20 extra marks from this program through his singing skills, he would not have got into Peking University. However, rural respondents were unable to derive any benefit from such programs. They demand cultural capital, such as art skills. Rural students who devote their entire time to academic studying do not have time to learn these skills. Besides, as their parents cannot teach them such skills, they can only acquire them by hiring private tutors or going on courses, both of which are too expensive for them.

Secondly, the lack of cultural capital limited rural respondents' choice of college selection. Some departments, such as fine art, require lower admission scores but require students to attend an admission interview and display their artwork. However, rural respondents are less likely to choose these programs because they may lack access to training in arts skills, lack the money to practice and have very limited knowledge beyond the textbooks. All these factors put them at a disadvantage in the admission interview.

This shortage of cultural capital will further decrease rural students' chance of attending elite universities under the university admission reform. In 2001, the ministry of education carried out the "Autonomous Recruitment Reform." This reform allows universities the right to decide their own admission examination and interview. A certain amount of the admission quotas are distributed via this autonomous recruitment scheme. By 2007, there were 57 universities participating in this reform (Zheng 2008). This reform disfavors rural students in two ways. Firstly, universities are only able to have examination or interview centers in some cities, some rural students may not be able to afford the transport and hostel fees. More importantly, as the autonomous recruitment reform stresses on allrounded students and inner qualities, it requires students to have various kinds of knowledge that rural students have difficulties in accumulating (Zheng 2008). For example, interview questions included pop songs and the environment of establishing business in the admission interview of Peking University and the Tsinghua University in 2015 (Beijing News 2015a, 2015b). Due to a shortage of cultural capital, rural students are less likely to outperform urban students during these interviews.

Due to the disadvantage of being a rural student, it is necessary to maintain the national college entrance examination. There is a hot debate around the reform of the university admission method. Some people think that the national college entrance 
examination fails to select all-rounded students (Zheng 2008). However, this examination requires less cultural capital. For rural students, it is a relatively fair way for them to compete with urban students.

Lastly, future studies should include poor urban students. A large group of poor urbanites are migrant workers. Some of them bring their children with them to the urban areas. As these children do not have an urban household registration but also cannot study in their village, the process of their education is very different from both rural and urban students. For example, some of them have to study in illegal schools set up especially for migrant workers' children and are not allowed to take college entrance examinations in the urban areas. As a result, the problems they face and the functions of their educational support network may be very different from regular rural and urban students. Therefore, it is essential to include this group in future studies.

Future studies should also investigate the difficulties that female rural students face in their educational attainment process. Traditionally, boys have a greater chance of attending school than girls (Hannum and Park 2007). This applies to some of our case studies, especially for ethnic minorities. Xiao Mei, an ethnic minority student, describes that "My father let me promote to senior high school only because my family do not need to pay tuitions and residential fees. My school covers all fees. Otherwise, he would not let me continue my schooling. I am the only girl who can promote to senior high school in my village. My other female classmates work at home or have already got married." We can see that being a girl may be a barrier for these students to access support for their schooling.

Competing interests

The author declares that there is no competing interest.

\section{Acknowledgements}

This research was substantially supported by a grant from the Research Grants Council of Hong Kong Special Administrative Region to Dr. Danching Ruan (HKBU 2447/06H). I want to thank Dr. Ruan Danching for her supervision and the following people for their invaluable help during my fieldwork in Beijing: Li Lan, Zhang Hao, Wang Linlan, Professor Fan Fumin, Professor James Lee, and Professor Yang Shanhua. I also want to thank all my respondents for sharing their stories with me.

Received: 1 July 2015 Accepted: 6 October 2015

Published online: 14 October 2015

References

Andreas, J. 2004. Leveling the little pagoda: the impact of college examinations, and their elimination, on rural education in China. Comparative Education Review 48(1): 1-47.

Beijing News. 2015a. 2015 the interview question of the autonomous recruitment scheme of Peking university. Beijing: Beijing News. 2015/06/14 (in Chinese).

Beijing News. 2015b. 2015 the interview question of the autonomous recruitment scheme of Tsinghua university. Beijing: Beijing News. 2015/06/17 (in Chinese).

Bernstein, DA, A Clarke-Stewart, EJ Roy, TK Srull, and CD Wickens. 1994. Psychology. Boston: Houghton Mifflin Company.

Bian, Y. 1994. Guanxi and the allocation of urban jobs in China. The China Quarterly 140: 991-999.

Blau, P, and JE Schwartz. 1984. Crosscutting social circles: testing a macrostructural theory of intergroup relations. New York, NY: Academic.

Brown, PH, and A Park. 2002. Education and poverty in rural China. Economics of Education Review 21: 523-541.

Buchmann, C, and E Hannum. 2001. Education and stratification in developing countries: a review of theories and research. Annual Review of Sociology 27: 77-102.

Coleman, JS. 1988. Social capital in the creation of human capital. American Journal of Sociology 94: 95-120.

DiMaggio, P. 1982. Cultural capital and school success: the impact of status culture participation on the grades of US high school students. American Sociological Review 47(2): 189-201.

Erickson, B. 2003. Social networks: the value of variety. Contexts 2(1): 25-31.

Fischer, CS, M Hout, MS Jankowski, SR Lucas, A Swidler, and K Voss. 1996. Inequality by design: cracking the bell curve myth. Princeton: Princeton University Press. 
Goyette, KA, and GO Conchas. 2002. Family and non-family roots of social capital among Vietnamese and Mexican American children. In Schooling and social capital in diverse cultures, ed. B Fuller and E Hannum, 41-72. Amsterdam: Elsevier Science.

Hannum, E. 1999. Political change and the urban-rural gap in basic education in China, 1949-1990. Comparative Education Review 43(2): 193-211.

Hannum, E, and A Park. 2007. Academic achievement and engagement in rural China. In Education and reform in China, ed. E Hannum and A Park, 154-172. London: Routledge.

Harris, AL, KM Jamison, and MH Trujillo. 2008. Disparities in the educational success of immigrants: an assessment of the immigrant effect for Asians and Latinos. In Exceptional outcomes: achievement in education and employment among children of immigrants, ed. P Fernandez-Kelly and A Portes, 90-115. Los Angeles, CA: Sage.

Herrnstein, RJ, and C Murray. 1994. The bell curve. New York: Free Press.

Kim, DH. 2005. Coping through social capital in educational stratification: relational alignment and complementary ties, Development and Society 34(1): 147-167.

Kim, DH, and B Schneider. 2005. Social capital in action: alignment of parental support in adolescents' transition postsecondary education. Social Force 84(2): 1181-1206.

Liang, C, J Lee, H Zhang, L Li, D Ruan, C Campbell, and S Yang. 2012. Silent revolution—social origins and university matriculation at Peking University and Suzhou University, 1952-2002. Social Sciences in China 193(1): 98-118.

Lin, N. 2001. Social capital: a theory of social structure and action. Cambridge: New York, NY.

Lin, N. 2008. Theory, measurement, and the research enterprise on social capital. In Social capital: An international research program, ed. N Lin and BH Erickson, 1-26. Oxford: Oxford University Press.

MacLeod, J. 1995. Ain't No Makin' It: aspirations and attainment in a low-income neighborhood. CA: Westview Press.

Mare, R. 1980. Social backgrounds and school continuation decision. Journal of American Statistical Association 75: 292-305.

National Bureau of Statistics of China. 2010. The 2009 population census of the People's Republic of China. Beijing: China Statistics Press.

National Bureau of Statistics of China. 2009. The 2008 population census of the People's Republic of China. Beijing: China Statistics Press.

Nicholas, T, A Stepick, and CD Stepick. 2008. Here's Our diploma, Mom! family obligation and multiple pathways to success. In Exceptional outcomes: achievement in education and employment among children of immigrants, ed. P Fernandez-Kelly and A Portes, 237-252. Los Angeles, CA: Sage.

Ono, H. 2004. In pursuit of college quality: migration decisions among college students in Japan. In Inequality across societies: families, schools and persisting stratification, ed. D Baker, B Fuller, E Hannum, and R Werum, 103-124. Amsterdam: Elsevier.

Perez-Pena, R. 2013. Colleges show uneven effort to enrol poor. The New York Times 30: A1.

Portes, A, and P Fernandez-Kelly. 2008. No margin for error: educational and occupational achievement among disadvantaged children of immigrants. In Exceptional outcomes: achievement in education and employment among children of immigrants, ed. P Fernandez-Kelly and A Portes, 12-36. Los Angeles, CA: Sage.

Qin, L, B Chen, and X Qin. 2013. Study on the impact of health on the earnings of migrant workers in China. Shijie Jingji Wenhui (World Economics Papers) 56(6): 110-120.

Schultz, TP. 1988. Education investment and returns. In Handbook of development economics, vol. 1, ed. H Chenery and TN Srinivasan. Amsterdam: North-Holland.

Shavit, Y, and HP Blossfeld (eds.). 1993. Persistent inequality: changing educational attainment in thirteen countries. Boulder: Westview Press.

Smith, SS. 2005. Don't Put My name on It: (dis)trust and job-finding assistance among the black urban poor. American Journal of Sociology 111(1): 1-57.

Son, J, and N Lin. 2012. Network diversity, contact diversity, and status attainment. Social Networks 34(4): 601-613.

Teachman, JD, K Paasch, and K Carver. 1996. Social capital and dropping out of school early. Journal of Marriage and the Family 58(3): 773-783.

Tsang, MC, and Y Ding. 2005. Resource utilization and disparities in compulsory education in China. The China Review 5(1): 1-31.

Wong, RS. 2002. Cultural and social capital in educational research. In Schooling and social capital in diverse cultures, ed. B Fuller and E Hannum, 161-170. Oxford: Elsevier Science.

Wu, X. 2007. Family resources and educational stratification: the case of Hong Kong, 1981-2001. Social Transformation in Chinese Societies 3: 173-201.

Wu, X. 2010. Economic transition, school expansion and educational inequality in China, 1990-2000. Research in Social Stratification and Mobility 28: 91-108.

Zhang, L, J Huang, and S Rozelle. 2002. Employment, emerging labour markets, and the role of education in rural China. China Economic Review 13: 313-328.

Zhang, J, Y Zhao, A Park, and Z Song. 2005. Economic returns to schooling in urban China 1988 to 2001. Journal of Comparative Economics 33: 730-752.

Zheng, R. 2008. Chinese college entrance examination: review of discussions and the value orientation of reforms. Front Education China 3(1): 137-148

Zhou, M, and CL Bankston III. 1998. Growing up American. New York: Russell Sage. 